\title{
Experiencia Cortázar: de una idea a crear un proyecto de narrativa transmedia
}

\author{
VERÓNICA TORRES \\ Universidad Nacional de Cuyo, Argentina \\ veronicahaydee2002@yahoo.com.ar \\ https://orcid.org/0000-0001-6372-9358
}

\section{Cortázar experience: from an idea to creating a transmedia narrative project}

\begin{abstract}
RESUMEN
La propuesta de narrativa transmedia Experiencia Cortázar

(2014-2016) permite un abordaje al escritor Julio Cortázar desde la perspectiva de un lector "cómplice y fanático" que invita a un recorrido biográfico y poético en Mendoza a mediados de 1940. Este trabajo es una descripción de su origen en 2014 y publicado en 2016 a partir de una serie de entrevistas a uno de sus creadores sobre el proyecto que se encuentra activo y está publicado en http://experienciacortazar.com.ar/. Pretendemos identificar los rasgos propios de la narrativa transmedia para experimentar otras formas de encuentro con lo literario desde la condición de participantes activos y colaboradores que se animen a introducirse en el universo literario y a realizar su propio recorrido por lo visual, los sonidos o la conjunción de distintos lenguajes que tienen como hilo al propio escritor. Esta invitación implica seguirlo a través de sus obras, fotos, amigos, lugares y así imaginar cómo fue la estadía del escritor en Mendoza o en otras ciudades, por lo cual esta propuesta pretende hacer más cercano y cotidiano a Cortázar en una relación autor-lector a partir de guiños cómplices e interactivos que son marca de época como consumidor proactivo que experimenta los cambios en el modo de interactuar con el hecho literario. Uno de los aspectos interesantes es que este proyecto aún está vivo, activo y continua ampliando sus pro-
\end{abstract}

puestas.

PALABRAS CLAVE

Narrativa transmedia; Experimentación literaria; Julio Cortázar; Interacción participativa.

\section{ABSTRACT}

The transmedia narrative proposal Cortázar Experience (2014-2016) allows an approach to the writer Julio Cortázar from the perspective of an "accomplice and fanatic" reader who invites a biographical and poetic journey in Mendoza in the mid-1940s. This work is a description of its origin in 2014 and published in 2016 from a series of interviews with one of its creators about the project that is active and is published at http://experienciacortazar.com.ar/. We intend to identify the characteristics of the transmedia narrative to experience other forms of encounter with the literary from the condition of active participants and collaborators who dare to enter the literary universe and make their own journey through the visual, the sounds or the conjunction of different languages that have the writer himself as their thread. This invitation implies following him through his works, photos, friends, places and thus imagining how the writer's stay was in Mendoza or in other cities, for which this proposal aims to make Cortázar closer and more everyday in an author-reader relationship from complicit and interactive winks that are a mark of the time as a proactive consumer who experiences changes in the way of interacting with literary fact. One of the interesting aspects is that this project is still alive, active and continues to expand its proposals.

\section{KEYWORDS}

Transmedia narrative; Literary experimentation; Julio Cortázar; Participatory interaction. 


\section{Introducción}

Los relatos nos han acompañado desde nuestros propios orígenes como especie; las palabras y las imágenes han transitado tantas transformaciones como tecnología se ha sumado a ellos en el arte de contar. Escritura, medios e imprenta convirtieron la musicalidad de la voz en la convivencia texto e imagen y la entrada en escena de la fotografía, el cine y la televisión, nos propusieron otras reglas en la narrativa visual en la que la imagen deja su lugar de complemento y disputa desde su particularidad como lenguaje un nuevo concepto de narrativa visual. Lo tecnológico ha atravesado de manera histórica los modos de entrelazar los hechos, pero, el placer de sumergirnos en una historia se ha mantenido en ese estado original. He allí, nuestro rol como lectores, devenidos actualmente en consumidores de historias y en "cómplices" que recomponen, completan, agregan y reconstruyen o trazan esas redes intertextuales casi invisibles que ha tejido un autor. La vertiginosa entrada de la Web 2.0 irrumpió con tal fuerza que modificó totalmente la relación íntima entre autor-lectorobra. La tecnología volvió a cambiar las reglas y la acción de contar se desplegó y abrió en una constelación de diferentes formatos textuales (documental, ficción, entrevistas, galerías de fotos, etc.) con las respectivas potencialidades de los lenguajes (imagen, sonido, texto) con los que narrar no se delimita a una forma tradicional y unidireccional: una profusión de voces, fragmentos, textos permiten tejer los hilos que los conectan desde los múltiples recorridos que permiten las plataformas digitales y que las redes sociales alojadas en las mismas multiplican como un eco, un nuevo significado de los relatos.

En este cruce del concepto de narración y los usos históricos de la tecnología (Paula Sibilia, 2017) surge la narrativa transmedia que desarma el concepto tradicional del relato ya que las formas convencionales del género no quedan intactas por el modo en que se entiende lo digital; se explotan sensaciones y experiencias en los recorridos de una historia, ahora multiplicada y simultáneamente transformada. De esta manera, hablar de un relato, implica no sólo entender como se cruza en la convivencia de lo analógico (un libro, por ejemplo) con lo que permite la web (un sitio web, una página de Facebook, una cuenta de Instagram, un acalorado debate en Twitter, una plataforma huésped de audiovisuales como YouTube, una playlist en Spotify) por mencionar no sólo las más accesibles sino también las que se han expandido y extendido en el universo de lo digital y que se encuentran al alcance de la mano (o en ella en los dispositivos móviles y diferentes pantallas con las que se interactúa a diario) sino también de entender los desplazamientos de los roles y lugares que en la tradición ocupaban autores y lectores, ahora entendiendo que entran en el juego los productores y el público en un papel activo y colaborador, y de manera conjunta, ingresan los desarrolladores de innovaciones tecnológicas que ofrecerán nuevas formas de relacionarse y de ser a través de las aplicaciones y redes sociales con las que una historia puede desarmarse, fragmentarse, recuperarse, completarse, reproducirse y compartirse ad infinitum dependiendo de la experiencia y la competencia digital de quien aborda (consume) la historia y de que tan atractiva resulte la propuesta y de la anticipación en su planteo de situaciones con las que pueda encontrarse este nuevo lector.

En relación al concepto de narrativa transmedia, nos encontramos con el caso de un grupo de lectores del escritor argentino Julio Cortázar que se transforman en creadores de un microuniverso transmediático para navegar a través de su obra, lejos de la tradicional secuencialidad que marcó la narrativa moderna pero retomando lo lúdico en una invitación a partir de pistas que llevan a descubrir la trayectoria del autor en la ciudad de Mendoza (Argentina) como antesala de lo que posteriormente se convertirán en los libros ícono de su estilo.

El proyecto Experiencia Cortázar nace en 2014 bajo la premisa de la existencia de mundo de los lectores apasionados por la obra literaria de este autor en el formato de un sitio web interactivo que pudiese ofrecer encuentros y recorridos a través de las producciones que están en plataformas de libre acceso por medio de las cuales se puede interactuar en diferentes niveles, acorde a las competencias digitales y tecnologías disponibles, asegurando básicamente una trayectoria general de la misma hasta, incluso, aportar sus vivencias como lectores y la íntima relación con los textos. En esta propuesta, los lectores fans están imaginados en la multitud de internautas, navegando frente a millares de islas virtuales que emergen y desaparecen con lo efímero de la novedad y lo lúdico del recorrido que inició en el 2014 como un proyecto multimedia con sede en Mendoza y que luego, se expandió a partir del concepto de colaboración a distintos puntos de Argentina alrededor del eje de la figura del escritor y sus obras.

Nuestro trabajo consiste en realizar una descripción en profundidad de esta propuesta transmedia desde su página de Facebook, las producciones que circulan en la plataforma de You Tube, las colaboraciones de los lectores a partir de la categoría narrativa transmedia y de lector/usuario "cómplice" como ha sido explicitado por sus creadores en el corte de 2018 a 2019.

Para concretar esta tarea, se tomará como fuente una entrevista realizada entre 2018 y 2019 a uno de creadores, Sergio Romero (UNTREF) quien define al proyecto como una propuesta de escritura colaborativa que parte de la experiencia individual del encuentro con la literatura de este escritor y cuyo punto de inflexión los convierte en "lectores cómplices" que devuelven a través de colaboraciones, las huellas de la influencia de estas lecturas en algún momento de su vida. Audios y canciones, fotos, fragmentos de la obra, códigos QR, referencias de las calles por las que deambulo el autor, listas de cuentos y pistas para reconstruir la vida en Mendoza en la 
década de 1950, etapa previa a las publicaciones de las antologías de cuentos y novelas se van articulando en ese ir y venir entre las distintas plataformas y la convocatoria a colaborar desde ese lugar inquisidor que sólo un lector fan puede articular de y sobre las obras de este escritor.

En síntesis, el proyecto Experiencia Cortázar propone otro modo de entender la relación autor-lector y lector-literatura y mundo posible a partir de estos aspectos colaborativos y particulares de lectores que sin ser específicamente expertos en literatura, en algún punto de su vida personal se cruzaron con la obra del autor y se encuentran en esta propuesta de narrativa que se retroalimenta de estas mismas experiencias personales a partir de la devolución de los fanáticos y de la posibilidad de sentir y disfrutar lo que apenas se entrega en las pistas ficcionales en continua referencia a un mundo compartido y sellado en los detalles de la música, las palabras, las calles, las ciudades, en definitiva, en una mitología que se construyó de boca en boca y que ahora navega de pestaña en pestaña hasta cumplir un raid como los cuentos y la rayuela que a mediados de los '50 del siglo pasado Cortázar entregaba a quienes serían sus lectores.

En estos momentos (2021), el sitio web está activo con la incorporación de nuevas producciones y la actualización de sus contenidos como audios, videos, página de Facebook, vías de contacto en la construcción de ese mapa imaginario de lectores. Durante 2018 y 2019, se realizó la prueba para realizar el recorrido del sitio web y aportar colaboraciones con 200 alumnos y alumnas del último año del Colegio Universitario Central (Don José de San Martín, Universidad Nacional de Cuyo), además formó parte de los actos celebratorios por el 80 aniversario de la Facultad de Ciencias Políticas Sociales (Centro Internacional de Estudios Visualidades, agosto, 2019) y caso de análisis en CIPECC (Gabriel Romero, Facultad de Filosofía y Letras, octubre, 2021).

\section{Narrativa transmedia}

Henry Jenkins es uno de los pioneros en establecer una relación entre narrativa transmedia y convergencia, e inicia las reflexiones acerca de este nuevo campo de estudio y sus posibilidades de realización enmarcado en un nuevo paradigma: el de la convergencia digital.

El término transmedia remite a lo tecnológico (plataformas, accesibilidad por el manejo de lo tecnológico y los costos) y modifica conceptualmente lo que entendemos por narrativa. Este punto sobre los desplazamientos del término narrativa es uno de los más interesantes, no sólo porque se apoya y emplea el esquema narrativo compartido por la comunidad sino porque lo abre, lo amplía y en este proceso de expansión le agrega elasticidad, plasticidad y permite cruzar las fronteras de lo verbal, lo icónico, lo verbal icónico y culmina la proposición de un múltiple lenguaje que al mismo tiempo requiere estrategias complejas de lectura y de producción.

Henry Jenkins (2008) introduce el concepto de convergencia a partir de las reflexiones de los procesos de convergencia tecnológica y convergencia cultural al explicar los cruces entre los avances tecnológicos como marcos materiales (tecnologías y circulación) con nuevas formas culturales de concebir la relación con la creación (producción) y la interpretación (como experiencia lectora o espectadora) ya no desde una posición pasiva sino como un colaborador, es decir, un destinatario activo y conocedor de la experiencia del ejercicio del derecho a opinar, transformar y finalmente a apropiarse de las obras, rompiendo definitivamente el contrato de lectura que los escritores habían modificado con la nueva narrativa desde el campo de la Literatura.

La narrativa transmedia se introduce en este marco no sólo en los cruces tecnológicos sino como una nueva modalidad de entender los relatos que transitan a través de lo que sostienen y portan las plataformas. En ellas se considera no sólo como una forma de contar sino como una de co-construir eso que se cuenta y como un modo de realizar esos recorridos a partir de decisiones que los usuarios pueden realizar o no y con ello agregar, compartir, intervenir en definitiva un texto.

La accesibilidad, plataformas, dispositivos y nuevas formas de construir los relatos no sólo están en relación con lo tecnológico sino con un cambio cultural como señala Jenkins en el que los roles no son manifestaciones estratificadas sino que en sus desplazamientos interpelan y ponen en debate quién produce (desde una mirada tradicional bajo el término de autor) y quien consume (éste último ya no conforme con un lugar pasivo sino como un colaborador que plantea aquello que en la producción en un estado inicial no ofrecía o no había desarrollado en esos aspectos que observa y detecta este mismo consumidor ahora convertido en productor-consumidor).

Sin embargo, quedan en debate no sólo las formas tradicionales de los medios como formas culturales y la relación con la audiencia (y desde esta perspectiva las discusiones en torno a la noción de autor sobre todo cuando se supera el simple posteo de información y se intervienen textos, videos, imágenes y con ello deja marcas de su propia interpretación) y el rol de los periodistas en un nuevo ida y vuelta con los ciudadanos que deciden registrar acontecimientos, compartirlos y darlos a conocer. Es evidente que cuando un usuario toma su celuLar y registra un evento lo hace desde una cultura compartida sobre lo que se considera que debe ser noticia (una cultura que forma parte de un esquema de contexto que es colectivo) y que al hacerlo circular en las redes plantea desde su perspectiva lo que debería ser considerado público.

Estas asiduas prácticas registran cambios culturales en el género periodístico no sólo en cuanto a la producción sino a la lectura acerca de la nueva forma de hacer periodismo. En esta 
nueva práctica cultural de la participación que a partir de la convergencia y de la tecnología permiten no sólo modificar el nivel de participación, los formatos textuales, los objetivos en cuanto al uso de los lenguajes y de cuál debería ser el rol de los medios, periodistas y destinatarios en este escenario. Así, se reconoce esta relación asimétrica entre consumidor y medio, más allá de las posibilidades que la tecnología ofrece para que puedas compartir, reproducir, desestimar en torno a lo que te proponen los medios como lectura de los acontecimientos.

Jenkins al referirse al proceso de convergencia y a relación con los medios, los nuevos y los tradicionales, no como una relación de desplazamiento sino como una de reconversión en la que los usuarios reconocen las viejas prácticas, pero desde una nueva mirada, la de la participación y la de la colaboración. Al referirse a este proceso de convergencia (...) " la historia nos enseña que los viejos medias nunca mueren, y ni siquiera se desvanecen. Lo que muere son simplemente las herramientas que utilizamos para acceder al contenido de los medios (el 8 track o la cinta de vídeo beta). Esta es lo que los especialistas en medias llaman tecnologías de distribución" (Jenkins, 2008, p. 24)

Por otro lado, Denis Renó y Sandra Ruiz (2012, p. 54) identifican a la narrativa transmedia como "una forma comunicativa contemporánea que actúa a partir de pilares fundamentales; entre ellos, la participación, la interactividad, la circulación por redes sociales y blogosfera, y la movilidad." Dentro de las características observan estos autores la participación en los procesos de producción, la posibilidad de acceder a los contenidos, pero también poder intervenirlos, agregar y transformar, en síntesis "la participación en los procesos, la retroalimentación de contenidos, la circulación por redes sociales, la movilidad y la intertextualidad entre contenidos." Rasgos que reconocen en las nuevas prácticas del periodismo digital abierto a nuevos actores sociales, los ciudadanos quienes a través de dispositivos móviles y aplicaciones que se pueden descargar, más la competencia para navegar en términos digitales, elementos que a raíz de la potencialidad de la globalización que permiten las redes y la accesibilidad son protagonistas en sucesos históricos como la primavera árabe, el escándalo de los desplazados de Siria, los bombardeos a Alepo, entre otros en la última década.

En síntesis, como señala Renó y Ruiz (2012, pp. 65-66) "La narrativa transmedia es un lenguaje que surge naturalmente en la sociedad, y cada día adquiere más fuerza entre los ciudadanos productores de información."

Como señala Roberto Igarza (2016) la transmediatización es el producto de una narración que circula en varias plataformas que recibe aportes de los consumidores por su rol activo y por la propia particularidad de espacio compartido que sostiene cada soporte; se entiende que un contenido producido no es el que circula simplemente por diferentes plataformas sino que cada una de ellas determina límites materiales que exigen una adaptación de ese contenido que puede ofrecer formas de recorrido que el usuario elegirá o no, ya que existe una propiedad de adaptación según la plataforma que la porta.

\section{Los nuevos usuarios}

Henry Jenkins vincula el nuevo paradigma con la novedad en el rol de los usuarios y el desafío que esto implica para los espacios de producción ya que

La convergencia exige a las empresas mediáticas que reconsideren los viejos supuestos acerca de lo que significa el consumo de los medios, supuestos que configuran tanto las decisiones de programación como de mercadotecnia. Si los viejos consumidores se suponían pasivos, los nuevos consumidores son activos. Si los viejos consumidores eran predecibles y permanecían donde les decías que se quedasen, los nuevos consumidores son migratorios y muestran una lealtad hacia las cadenas, las redes y los medios. Si los viejos consumidores eran individuos aislados, los nuevos consumidores están más conectados socialmente. Si el trabajo de los consumidores mediáticos fue antaño silencioso e invisible, los nuevos consumidores son hoy ruidosos y públicos. (Jenkins, 2008, p. 25)

Por otra parte, Fátima María Gutiérrez (2012) explica que en este nuevo paradigma existe un nuevo usuario participativo y colaborativo, básicamente creativo. El acceso a internet, la posibilidad del consumo en espacios domésticos y personales, la accesibilidad y la variable y abundante producción de contenidos audiovisuales y de programas que se pueden descargar, sencillos y de fácil aplicación lleva a esta nueva audiencia a interactuar con múltiples canales, modos y plataformas.

Las nuevas tecnologías ofrecen mayor flexibilidad y movilidad, por lo que permiten la gestión de cualquier actividad en cualquier lugar. Con la difusión de herramientas que hacen posible la participación en los procesos de producción, edición y distribución de información y contenidos, el consumidor se convierte al mismo tiempo en creador activo con capacidad para contribuir y compartir múltiples visiones del mundo en el que vive. (Castells, 2001, p. 187)

Esta nueva audiencia está vinculada al uso de redes sociales, y como contexto de producción, Fátima María Gutiérrez (2012) observa que las particularidades de la oralidad que forman parte de las interacciones en las conversaciones se filtran en el uso de las redes sociales y no permite pensar que aun operando con la escritura se lo piense como texto escrito sino como uno dentro del paradigma conversacional que compartimos colectivamente, al mismo tiempo difumina la separación entre público y privado porque se vuelven públicas conversaciones, opiniones, comentarios a través de las operaciones de participar y compartir.

En las redes sociales se entremezclan los intereses personales con los intereses profesionales: el mero hecho 
de compartir fotografías de carácter privado y álbumes de música preferidos no es más que una manera de la búsqueda innata del deseo de conectarse con el otro, de generar comunidades virtuales, de darse a conocer $y$, por qué no decirlo, de seducir y de provocar un estímulo a las nuevas audiencias. (Gutiérrez, 2012, p. 31)

Un primer punto que este caso manifiesta serán los cambios en las estrategias de lectura, las formas de abordaje y los recorridos a través de plataformas de un relato que se expande y se modifica hasta transformarse en otro y en otro y cuyos puntos de enlace serán los usuarios consumidores devenidos a productores en algunos casos (según nivel de experticia, accesibilidad tecnológica e interés), un relato base o cero y las posibilidades de abordar este relato desde diferentes lenguajes.

En los casos en que el consumidor se convierte en productor a través de instancias de retroalimentación (además de abrir posibilidades de lectura, compartir, hacer circular, estarían las que refieren a una intervención más activa) en los que existe un comportamiento colaborativo (participación) que deja sobre la mesa de debate mantener o no en sus particularidades tradicionales la noción de autor y la del control en la circulación de los textos según una accesibilidad pautada.

Jenkins (2008) señala en relación a la convergencia mediática, que existe un flujo de contenidos que se desplaza a través de múltiples plataformas. Las prácticas culturales según Jenkins están caracterizadas no sólo por este flujo de contenidos sino también por la cooperación entre múltiples industrias mediáticas y un comportamiento migratorio de las audiencias que manifiesta la intención de desplazarse en busca de un tipo de experiencias de entretenimiento. Por ello, la convergencia es desde la perspectiva de este teórico una respuesta que materializa un cambio cultural porque existen estímulos que provocan a los consumidores a desplazarse en busca de nueva información relacionada con la planteada originalmente teniendo como objetivo el establecer relaciones o redes de conexión entre los contenidos que puedan encontrarse dispersos.

\subsection{Los cambios de estrategia de lectura en la Narrativa transmedia}

A partir de la relación tecnología-usuario y la ruptura del concepto tradicional de narración, el contrato de lectura dinamiza nuevas estrategias en el proceso de interfaz con las pantallas. Esto implica que los participantes establecen nuevas formas de interactuar entre sí y que esas reglas responden a ese cambio cultural de tal manera que ni el consumidor es tan pasivo ni es tan asimétrica la relación del productor con él, aunque se mantenga cierto desequilibrio en torno a la participación y la creación. Los textos forman parte de una red mayor que se manifiesta a partir de estas migraciones. La relación entre estos textos nos recuerda la noción de dialogicidad acuñada por Bajtín (1990) en la década del '30. Acorde a este concepto, la producción literaria permitiría que el lector reconozca a otros textos que sirven como base y las marcas de lectura y contexto que un segundo autor le imprime a su propio texto al incluir ese texto base que es reconocido por la comunidad.

Desde la mirada de la comunicación digital, Landow (2009) toma la noción de hipertexto a partir de la definición que realiza Roland Barthes como un texto compuesto por fragmentos de texto (lexías). Estas lexías forman este texto junto a los enlaces electrónicos que los conectan entre sí.

La expresión hipermedia simplemente extiende la noción de texto hipertextual al incluir información visual y sonora, así como la animación y otras formas de información. Puesto que el hipertexto, al poder conectar un pasaje de discurso verbal a imágenes, mapas, diagramas y sonido tan fácilmente como a otro fragmento verbal,

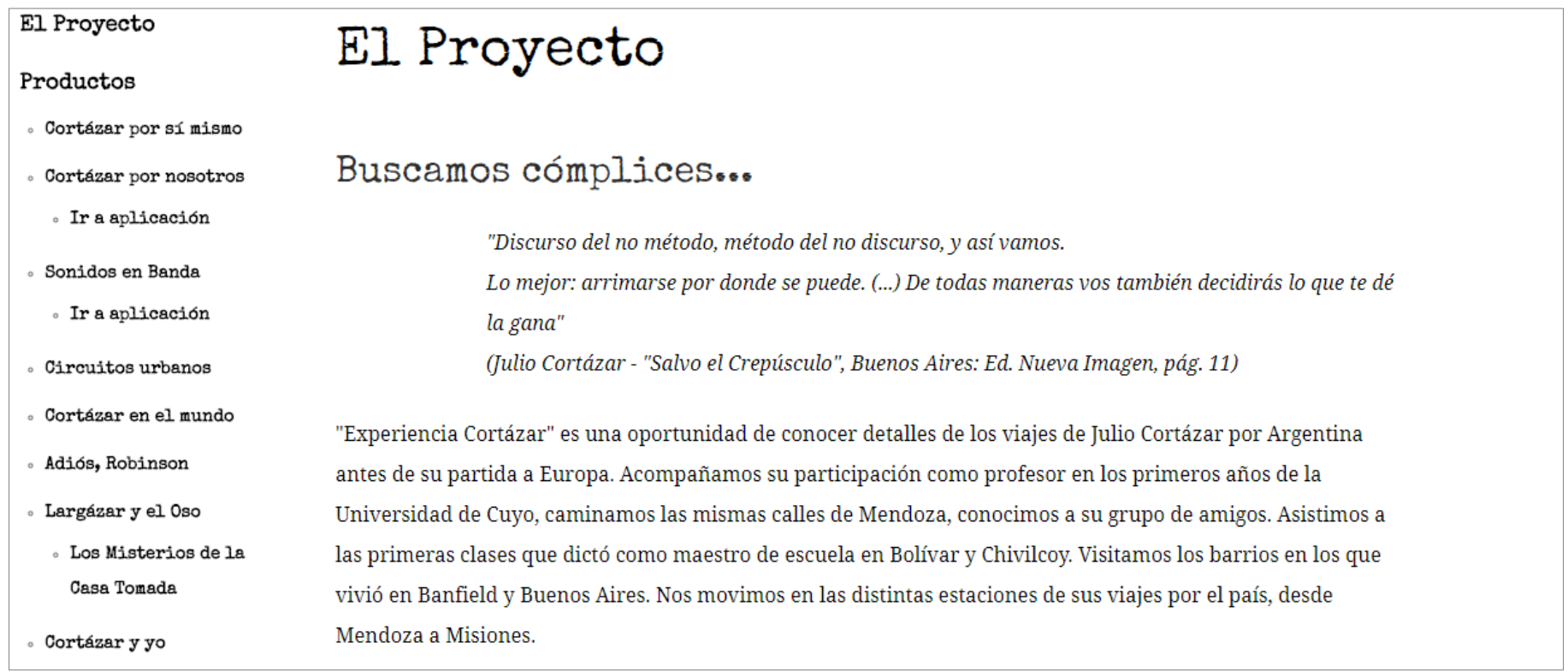

Figura 1. Página de presentación del proyecto en http://experienciacortazar.com.ar/index.php/sobre-el-proyecto 
expande la noción de texto más allá de lo meramente verbal, no haré la distinción entre hipertexto e hipermedia. (Landow:, 2009, p. 25)

Más adelante agrega que la relación entre hipertextualidad que puede estar materializada a través de los diferentes lenguajes, al ser accesible a través de medios informáticos tiene claves de acceso por medio de las palabras que están en lugar de eso que se menciona o nombra por decirlo semióticamente. Las palabras son esas claves de acceso que se vinculan a través de enlaces que llevarán a una lectura lineal o a una multilineal según sean las opciones del lector. Seguir en el texto base u original o moverse a través de los vínculos en los términos (lexías) y en cada recorrido se modifica la estrategia de lectura en este continuo avance que abren los enlaces.

Con hipertexto, pues, me referiré a un medio informático que relaciona información tanto verbal como no verbal. En esta red, emplearé los términos hipermedia e hipertexto de manera indistinta. Los enlaces electrónicos unen lexias tanto «externas» a una obra (por ejemplo, un comentario sobre ésta por otro autor o textos paralelos o comparativos) como «internas» y así crean un texto que el lector experimenta como no lineal o, mejor dicho, como multilineal o multisecuencial. Si bien los hábitos de lectura convencionales siguen siendo válidos dentro de cada lexía, una vez que se dejan atrás los oscuros límites de cualquier unidad de texto, entran en vigor nuevas reglas y experiencias." (Landow, 2009, p. 25)

\section{Narrativa transmedia: el caso de Experiencia Cortázar}

\subsection{El alcance de la propuesta}

El proyecto propone la utilización de la producción de contenidos de forma gratuita tanto de manera individual como institucional (por ejemplo, dirigido hacia aquellos que forman parte de medios de comunicación como emisoras de radio y televisión) entendiendo que el reconocimiento de la autoría de quienes realizaron los guiones, producciones y diseñaron el sitio es la única condición tanto para realizar la difusión como para descargar sus contenidos. Desarma de hecho las limitaciones al acceso a una plataforma (técnicas o económicas) al ofrecer los contenidos mediante la solicitud vía mail a quien desee trabajarlos y se abstiene de responsabilizarse o implicarse en las posibilidades de una obra derivada surgida de los usuarios del sitio web.

En el contrato de lectura, la cláusula del uso y acceso del material sólo incluye estas condiciones que podemos encontrar al abrir la pestaña "Invitación y condiciones de participación": "Todos los materiales publicados por Experiencia Cortázar están a disposición de los medios en forma gratuita y podrán ser difundidos, de acuerdo a las siguientes condiciones:

\subsection{Nuevos lectores, nuevos abordajes}

Un primer punto que este caso manifiesta serán los cambios en las estrategias de lectura, las formas de abordaje y los recorridos a través de plataformas de un relato que se expande y se modifica hasta transformarse en otro y en otro

\section{Largázar y el Oso}

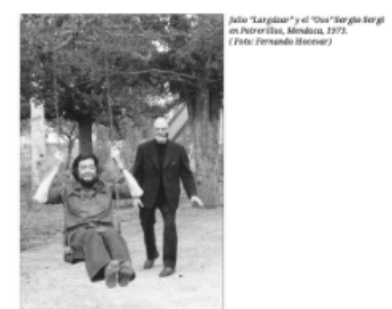

Julio Cortázar, y Sergio Sergi y su familia forjaron una amistad a mediados de los años cuarenta, que se mantuvo viva hasta el final. Así lo atestiguan los documentos que...

Leer más

\section{Cortázar por nosotros}

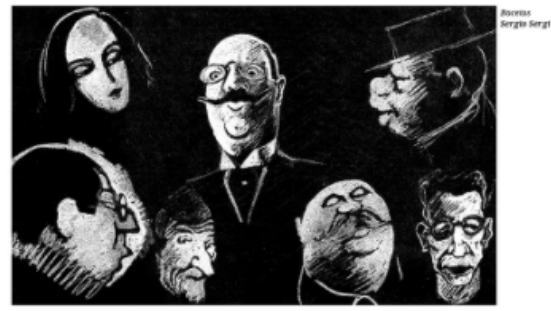

En esta sección se ven los resultados de la plataforma colaborativa en donde se reescribieron algunos textos de Julio. Leer más
Sonidos en banda

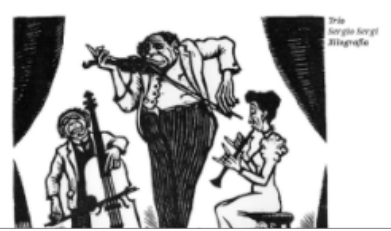

Cortázar y yo

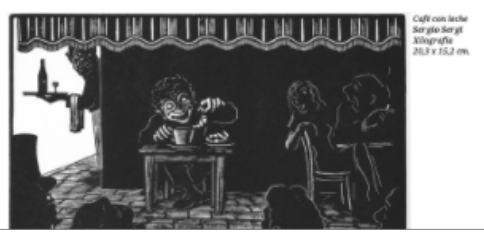

Figura 2. Propuesta de desplazamiento según lo que busca el lector: se interactúa a través de la interfaz: más pantallas más posibilidades de desplazarse y construir otros recorridos y relatos. 
y cuyos puntos de enlace serán los usuarios consumidores devenidos a productores en algunos casos (según nivel de experticia, accesibilidad tecnológica e interés), un relato base o cero y las posibilidades de abordar este relato desde diferentes lenguajes.

En los casos en que el consumidor se convierte en productor a través de instancias de retroalimentación (además de abrir posibilidades de lectura, compartir, hacer circular, estarían las que refieren a una intervención más activa) en los que existe un comportamiento colaborativo (participación) que deja sobre la mesa de debate mantener o no en sus particularidades tradicionales la noción de autor y la del control en la circulación de los textos según una accesibilidad pautada.

Jenkins (2008) señala en relación a la convergencia mediática, que existe un flujo de contenidos que se desplaza a través de múltiples plataformas. Las prácticas culturales según Jenkins están caracterizadas no sólo por este flujo de contenidos sino también por la cooperación entre múltiples industrias mediáticas y un comportamiento migratorio de las audiencias que manifiesta la intención de desplazarse en busca de un tipo de experiencias de entretenimiento. Por ello, la convergencia es desde la perspectiva de este teórico una respuesta que materializa un cambio cultural porque existen estímulos que provocan a los consumidores a desplazarse en busca de nueva información relacionada con la planteada originalmente teniendo como objetivo el establecer relaciones o redes de conexión entre los contenidos que puedan encontrarse dispersos.

\subsection{El inicio de la experiencia}

La propuesta narrativa fue una producción del Laboratorio de Contenidos Digitales Audiovisuales (Ce De A Lab y la Universidad Tecnológica Nacional, Facultad Regional San Rafael en co-producción con unidades académicas dentro de las carreras de Comunicación y Producción en Medios (Universidad Nacional de Cuyo) y la Universidad Nacional de Misiones, entre otras. Tuvo una primera etapa de producción entre 2014 y 2017 y su director responsable es Sergio Romero.

Sergio Romero, forma parte junto con Hernán Cazzaniga del equipo de dirección, diseño, diagramación y producción que dio vida a "Experiencia Cortázar". Para comenzar a pensar en esta propuesta consideró las características de la convergencia, de ellas, Romero ${ }^{2}$ focaliza las que implican el flujo de contenido a través de múltiples plataformas mediales, la colaboración de múltiples sectores productores de contenido y el comportamiento «migratorio» de las audiencias de los medios. Basado en las reflexiones teóricas de Jenkins, la convergencia exige, entonces, el ajuste y la reconfiguración de los modelos de narración y producción de los productos, y de la participación de las audiencias.
Como proyecto transmedia, implica diferentes medios en los que los lenguajes de cada uno forman parte de las restricciones materiales en cuanto a la producción de contenidos pero que entre todos forman un sistema integrado de información de comunicación. Los contenidos que se producen están disponibles en diferentes plataformas tecnológicas y se administra el relato pensando en audiencias diferentes conforme a diversas plataformas desde las que se puede tener acceso. El eje temático en común de este relato consiste en rastrear a Julio Cortázar a través de sus obras y las continuas referencias a su vida en diferentes lugares, sus relaciones familiares e intelectuales, inicialmente en Mendoza que luego se abrió a realizar esa búsqueda en otras ciudades de Argentina. Por otra parte, la posibilidad de interactuar permite no sólo acceder a los contenidos sino también a producir y, con ello, incorporarse a este relato sobre las experiencias entre lectores y Julio Cortázar ya desde la categoría de autores.

\section{4. ¿Cómo nace Experiencia Cortázar?}

Sergio Romero en la entrevista (mientras despliega al unísono las pantallas y los dispositivos que coloca uno en la mesa) explicó cuáles fueron los aciertos, los puntos a evaluar pasada la primera parte de la concreción del proyecto y cómo seguirían los tramos para "colgar" las producciones de documentales y videos de quienes se animaron a responder al llamado a ser "cómplices". Podríamos señalar que este proyecto tuvo una etapa de armado de la logística, preparación del equipo, incorporación de instituciones en este entramado y la producción. Una segunda etapa de difusión y de establecimiento geográfico, tanto local como virtual y la realización de las producciones. Ubicamos entre el 2014 y 2016 este momento.

Por otro lado, un tercer momento (2017) en el que la página queda activa en la que se registran nuevas entradas de usuarios nuevos, En esta etapa se encuentran los creadores: analizando, evaluando y procesando todo el material que se está editando para que sea subido. Las circunstancias externas como presupuestos y convenios firmados entre instituciones dejaron en suspenso entre el 2017 y 2018 la producción, sin embargo, queda mucho material para editar y "subir", pensando en hacer una devolución a quienes aceptaron el juego. Pero ¿cómo nació? Este proyecto de narrativa transmedia nació como un homenaje al escritor argentino Julio Cortázar desde la mirada de un lector fan se remonta a los años universitarios de Romero, el recuerdo de un escritor que fue profesor en Mendoza queda anidado bajo la figura de un proyecto audiovisual: ambicioso y en colaboración con Julio Bertolotti, años después será parte de la propuesta inicial a los otros miembros del equipo que se irán incorporando.

\subsection{Los lectores cómplices}

Cuando se inició el proyecto se partió de diferentes puntas y aspectos; distintos senderos y trayectorias confluyeron en 
la concreción de un relato transmedia en el que participaron literatos, sociólogos, comunicadores, expertos en medios, educadores y artistas que lo que tenían en común era la categoría de "fan" como fanático, admirador y un poco más: cómplices de otros fanáticos del escritor, de su literatura y de la mirada sobre la literatura. Le consultamos a Sergio Romero ${ }^{3}$ , sobre el destinatario imaginado en el proyecto inicial y el que finalmente se incorporó a esta propuesta: uno y otro en definitiva estaban pensados desde un perfil de fan que tuviera el plus de cómplice y con ello las respuestas estuvieron al alcance de lo tecnológico, de lo humano y de la diversidad en cuanto a las formas de aceptar los desafíos propuestos.

Así un proyecto de narrativa transmedia no sólo implica lo que un equipo desea relatar, sino que debe pensar en quiénes podrán participar. Acceso a plataformas, los avances tecnológicos pero el perfil de un usuario abierto, sin límites, cuya característica consistiría en animarse a participar, interactuar y producir en este juego doble entre literatura, autor y lector, por un lado y entre obra, experiencia y lectura por otro. Si bien, el perfil en el que se pensó en las etapas iniciales del proyecto que comienzan a concretarse en el 2014 nos habla de un internauta fan y cómplice, se agrega un dato no menor: un corte etario de estos lectores adultos jóvenes que tuvieron en sus propias experiencias de vida un contacto con el escritor a través de sus obras. Por lo tanto, desde el equipo de producción se inicia la búsqueda de los otros admiradores cortazianos diseminados en Europa y Argentina.

"Lo que buscamos era un usuario amplio porque el concepto de usuario que nosotros definimos era fan, por eso el slogan es dice "buscamos cómplices" y eso fue muy orientador; y algunas cosas de las mejores se lograron fueron en base a ese concepto. Hay un material que aún no subimos en plataforma que pudimos conseguir de co-creación en el nivel más alto de colaboración. Es un grupo de fans en Europa y de Argentina que liga entre la nostalgia argentina, su nostalgia por su juventud en los 70 y la pasión por Cortázar. Esas nostalgias las anudan frente a esta experiencia la toman y empiezan a hacer cosas que estaban dentro del universo narrativo, pero no estaban pensadas por el equipo que organizó la experiencia."

\subsection{El proyecto}

¿Cómo nace este proyecto? En principio, el equipo responsable formaba parte de una productora audiovisual y esto también nos dice cuál era la idea original, en carpeta, el objetivo consistía en llegar a un filme. Es para Sergio Romero, un antiguo deseo que permanece, aunque se tarde en concretarlo.

Una obsesión mía. Yo estudiaba Letras en 1981. Mientras curso con la profesora Dolly Lucero, ella me comenta que Cortázar vivió en Mendoza y que fue profesor en esta facultad, que había alumna de él y que había recibido libros de regalo. Eso a mí me obsesionó mucho. Como

\section{Migración de contenidos}

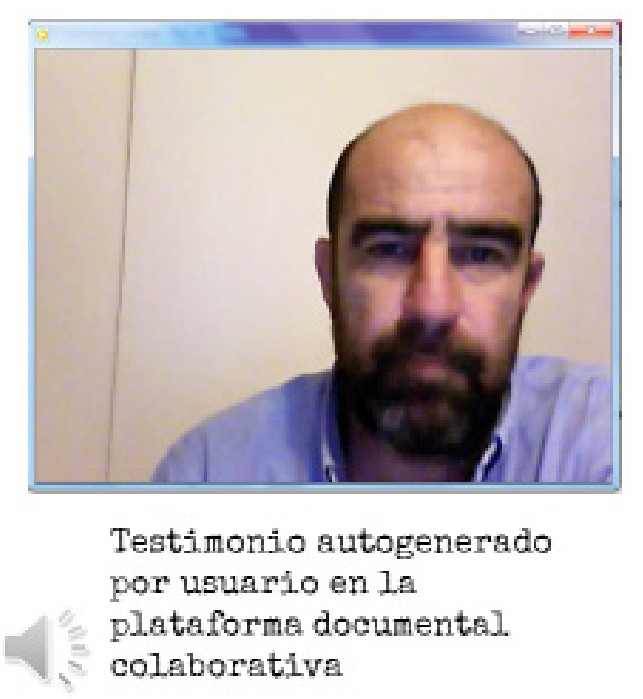

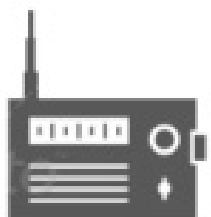

Micro de radio

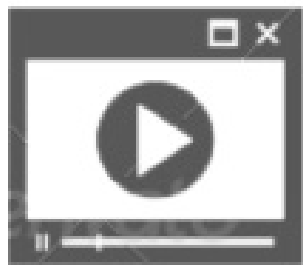

Web doc

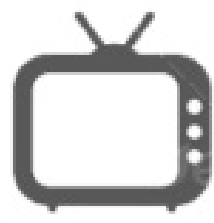

Micro de TV

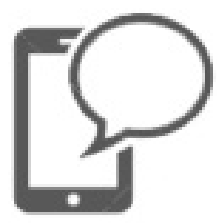

Acceso localizado vía LBS

Figura 3. Conceptualmente la experiencia transmedia implica la migración de contenidos de una plataforma a otra, en este caso una producción realizada por un "cómplice" da cuenta de lo que significó en su vida el cruce con Cortázar. Para los realizadores, este testimonio que aún no se sube a la página significa el cierre del proyecto en su etapa inicial. El testimonio corrobora la participación, el uso de tecnologías y el principio básico del proyecto: una transmedia orgánica 
yo había leído a Cortázar me empiezan a sonar ciertas referencias a Mendoza, por ejemplo, datos que lo ubican en Uspallata y todavía no estaban las obras póstumas. Cuando sale la obra póstuma y yo leo "El examen" y "El diario de Andrés Fava" reconozco esas referencias autobiográficas y en ellas su relación con Sergio Sergi. Y por otro lado yo soy un fanático de Sergio Sergi ${ }^{4}$ de siempre que lo conocí a través de sus grabados y a través de otras circunstancias llegamos a conocer a Hocevar (hermano menor del artista Fernando Höcevar) y, pienso en que un día filmaré una película. Me dediqué a la producción audiovisual y en 2009, escribo el proyecto y lo presentó con un amigo para ganar un fondo para hacer la filmación. Ese proyecto era Largazar y el Oso, pero no lo hacemos porque no estaban las condiciones económicas dadas para hacer ese tipo de película en Mendoza. Sigo trabajando ese modelo y finalmente con Julio Bertolotti decidimos realizarlo como modelo transmedia. Los dos estábamos en distintas universidades, existían experiencias en radios; apareció Hernán Cannizari y acá en Mendoza Graciela Dístefano y su equipo y ya se armó. Se armó un camino de producción de pequeños elementos digitales baratos para ir construyendo identidad del proyecto y audiencia que te permiten llegar a conseguir fondos para cosas más caras. (Entrevista a Sergio Romero. Mendoza, 18/6/2018)

Así, ya en la producción, el esquema de las actividades plantea cinco partes: tratamiento de la parte literaria, especificaciones funcionales (descripción de la experiencia del usuario. por ejemplo), especificaciones tecnológicas (establecer cuáles son los productos mediales) y especificaciones de diseño y el plan de negocios, es decir cómo se conseguirán los fondos para lograr concretar el proyecto. Dentro de las especificaciones funcionales existe un cuadro de doble entrada en el que se desarrolla la experiencia por producto, plataforma y público.

\subsection{Descripción}

"Experiencia Cortázar" además de tener accesibilidad y vigencia en la web, se realizó dentro del marco del homenaje al escritor argentino en el centenario de su nacimiento y que puso en disponibilidad el registro y la participación de eventos como un radioteatro en vivo en LRA Radio Nacional o la posibilidad de compartir textos, agregar videos, escuchar al mismo Cortázar hablar de su obra.

Esta experiencia transmediática permite la confluencia de lectores, obras, calles mendocinas y rincones familiares y a la vez misteriosos de la creación literaria. Como su nombre lo indica,

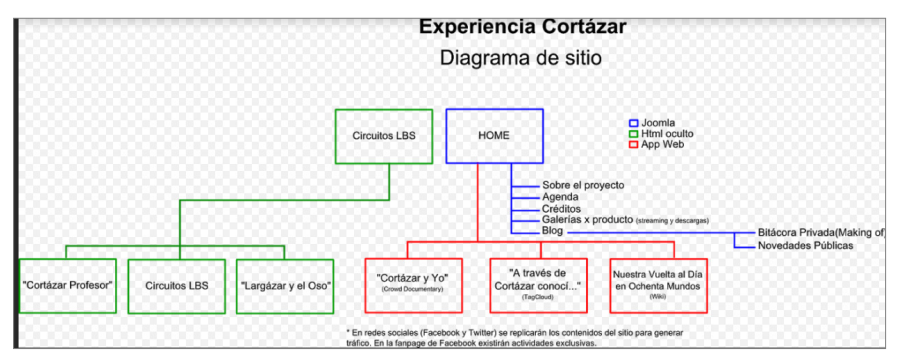

Figura 4. Esquema de diagramación. Elaboración propia. la propuesta es experimentar a través de recorridos urbanos, musicales, literarios y profundamente personales la literatura de Julio Cortázar y, en particular, reconocer desde los umbrales de la familiaridad con el escritor los aspectos más personales de su estancia en Mendoza. En consonancia con la variación de sensaciones, se pretendió entre 2014 y 2016 la colaboración, participación de los lectores, en muchos casos declarados "fans" a realizar recorridos que con un guiño cómplice y lúdico pudieran meterse en la piel y los zapatos de un joven profesor que a fines de los '40 vivió durante algunos años en Mendoza y que, a la postre se convirtió en eximio creador de mundos posibles coloreados por bestiarios y rayuelas fantásticas.

Desde que uno teclea las palabras de acceso en una de las plataformas se abre un abanico de posibilidades para comenzar a investigar qué es "Experiencia Cortázar", blog, Facebook, entrevistas a sus protagonistas, notas a sus creadores (entre los que mencionaremos a Sergio Romero -responsable de contenidos de Canal Acequia y María Cantero, diseñadora especializado en diseño web) menciones y textos que remiten y se abren como hojas en un libro a la curiosidad de quien sin ser un asiduo lector siente la intriga que abre la palabra "experiencia" como vivir como otro y al mismo tiempo ser uno mismo.

En el imaginario cultural local mencionar al escritor es nombrar una estrella en el universo de escritores reconocidos por su talento a la hora de relatar dejando verdaderas trampas lingüísticas que han deleitado por generaciones a muchos; sin embargo, y es parte de una realidad, al mismo tiempo que se rinden homenajes a Cortázar su sólo nombre genera distancia entre quienes no son asiduos lectores y, ahí, radica, en parte la propuesta de este relato compuesto al ritmo de los lúdicos saltos de la rayuela: empezar a transitar esta experiencia como vecino de Mendoza, como curioso y como cercano a un escritor que universaliza los rincones de las palabras. Y, como invitación a vivir otra vida es una propuesta de una ruta plena de sensaciones y vivencias que sólo este microuniverso delineó no sólo como texto sino como parte del juego que un autor y un lector juega.

Observamos que en el acceso a la plataforma se registran por ejemplo las opciones: "Cortázar por sí mismo" que ofrece la posibilidad de escuchar audios del propio escritor hablando de su poética, sus temas, su quehacer literario. El enunciado directivo "Ir a aplicación" como "Sonidos en banda" o "Circuitos urbanos" proponen no sólo participar sino vivenciar lo que le da un plus de realismo al acceder y aceptar la experiencia.

\section{La experiencia con los QQ ${ }^{5}$}

"(..) esa fue la primera experiencia que nosotros vivimos con el sistema porque (bueno por una cuestión burocrática de que la municipalidad de la Ciudad de Mendoza no nos terminó de cerrar el tema de la ubicación de los QR, terminamos dejando pistas en soporte papel. Lo interesante fue cuando decidimos 

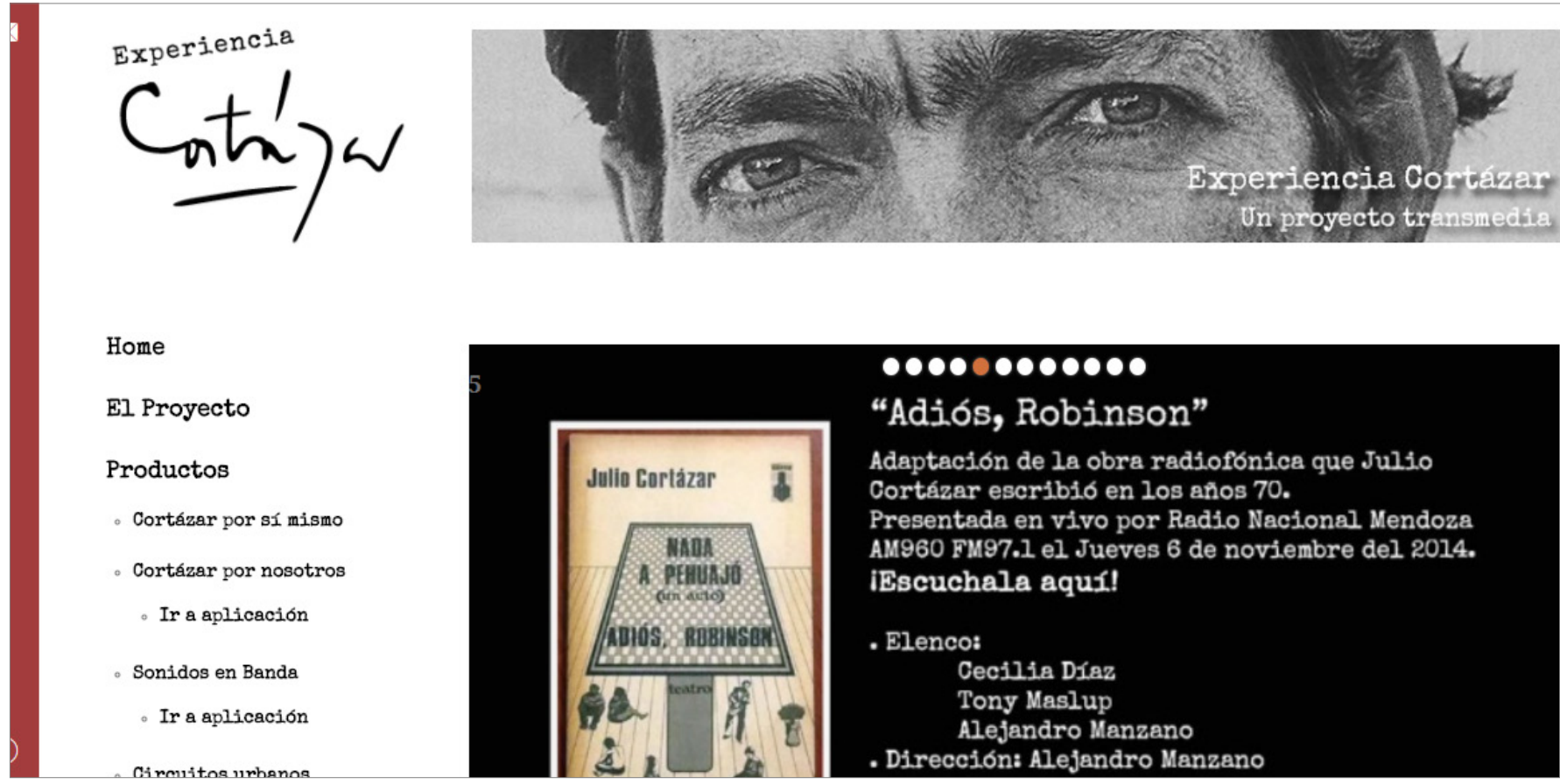

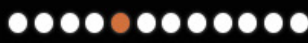 \\ "Adiós, Robinson"}

Adaptación de la obra radiofonica que Julio

Cortázar escribió en los años 70.

Presentada en vivo por Radio Nacional Mendoza

AM960 FM97.1 el Jueves 6 de noviembre del 2014.

iEscuchala aqui!

- Elenco:

Cecilia Diaz

Tony Maslup

Alejandro Manzano

- Dirección: Alejandro Manzano

Figura 5. Portada del blog Experiencia Cortázar. http://www.experienciacortazar.com.ar/

hacer la transmedia wiki en la Facultad de Ciencias Políticas, decidimos llevar los QR desvinculados de la estructura. Lo que pasa es que los QR que yo había elegido estaban diferenciados en locación significativas y estaciones de tránsito y si hay entre una locación y otra una diferencia de cinco cuadras, por ejemplo, no podés dejar sólo al usuario esas cuadras, entonces en el medio armás una que no es significativa. Invertimos la experiencia, ésas (las de tránsito) estaban de relleno y ésas fueron las importantes que llevamos a la Facultad y las pegamos en distintos lugares y armamos algo así como una búsqueda del tesoro."

Esta experiencia de geolocalización implicó seguir estas locaciones significativas señaladas en las de tránsito y que los usuarios al llegar realizaran un breve registro con fotos en el

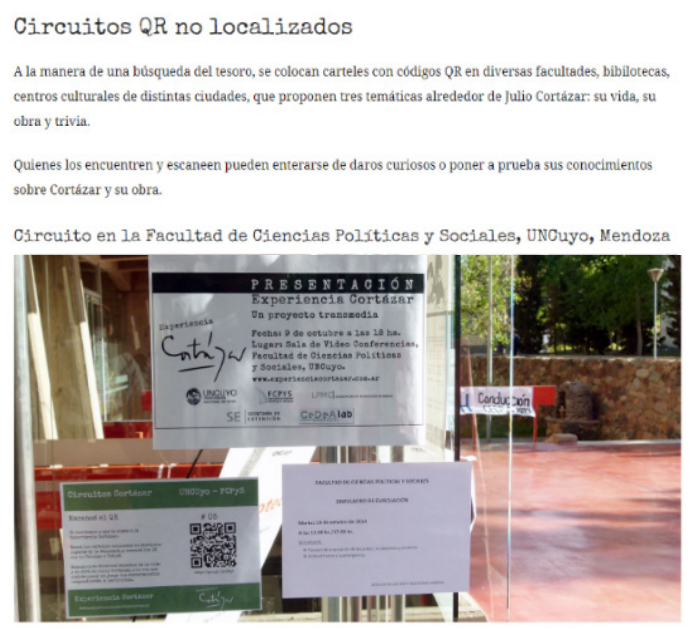

Figura 6. fotografía de las pistas para los lectores puedan resolver los acertijos que incluían los mapas en la ciudad de Mendoza como recorrido diario de Cortázar durante su estadía en la provincia. lugar y las subieran a la página; y esto se repitió en otras ciudades del mundo: Colombia y Barcelona.

Sergio Romero 6 al hablar de este producto evalúa a distancia que luego de finalizada la primera etapa (2014-2016) la respuesta de quienes aceptaron el desafío lúdico superó la expectativa de sus creadores, aunque en ese momento, apenas terminada la presentación de la plataforma, aparentaba no haber logrado a simple vista una gran participación. "Creo ahora sí fue una experiencia exitosa, aunque en ese momento, apenas terminamos, pensábamos que no había sido exitosa."

Como señala Fátima M. Gutiérrez, compartir el archivo fotográfico de Sergio Sergi con Cortázar barre esa frontera entre lo familiar y privado para que se transforme en familiar para los usuarios que conocen aspectos más íntimos y personales del escritor y público al permitir en la navegación agregar tramos y recorridos y con ello crear un espacio compartido para quienes desean sentir aún en sus rutinas que han seguido los pasos cortazianos.

\subsection{Experiencia Cortázar: cercanía y cotidianeidad}

Al introducirnos en la propuesta, el sonido (lo verbal, el sonido ambiental y la música) estimula el recorrido que como lectores podemos realizar de la obra.

\section{Cortázar por sí mismo}

Son audios e incluye sonido ambiental que identifica el oficio del escritor (tecleo de la máquina de escribir) con un contexto temporal de la radio (el sonido de una púa gastada), lo verbal: el locutor y fragmentos de una entrevista que RTE le hizo al escritor: 


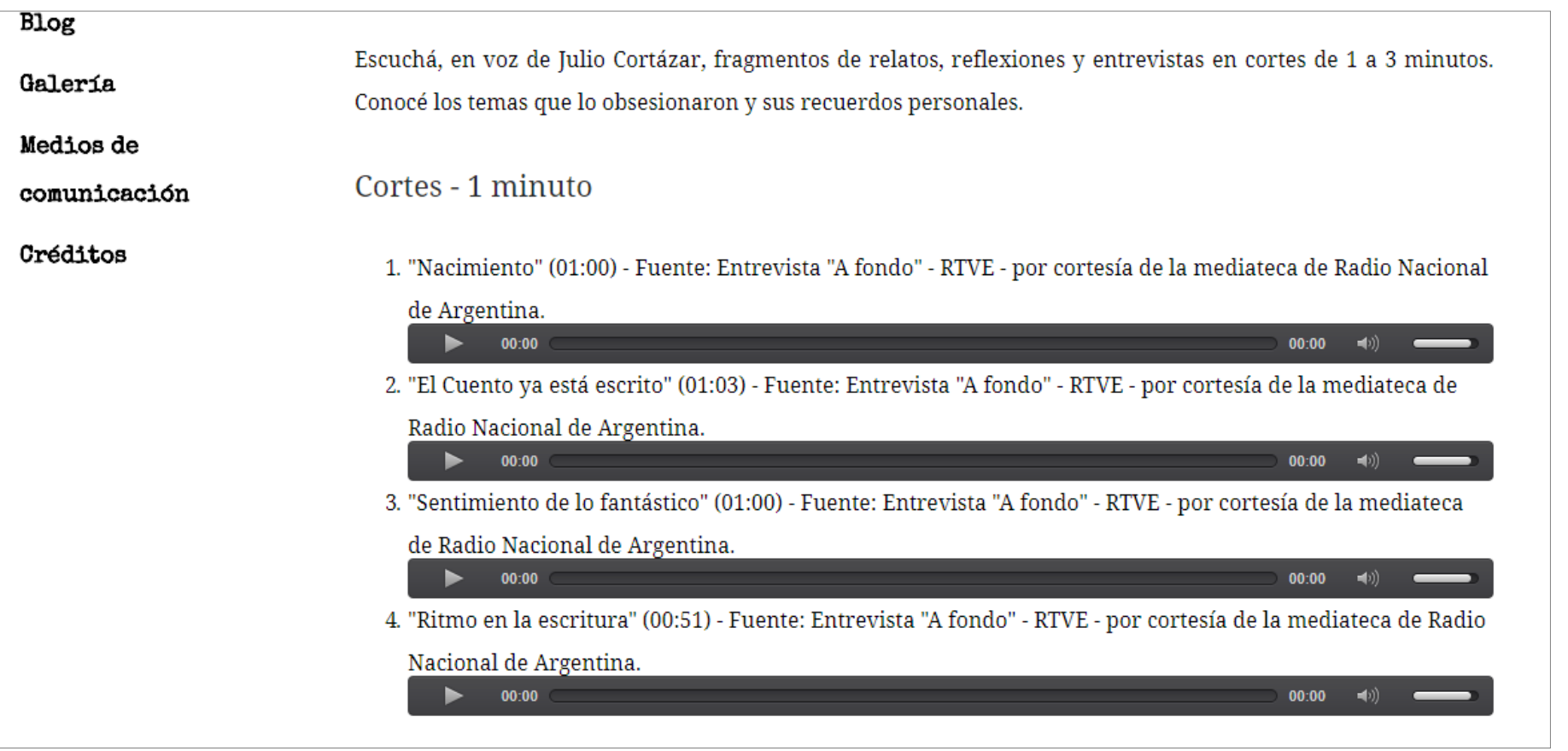

Figura 7. Los audios "Cortázar por sí mismo": los ciberlectores se desplazan y escuchan en audios fragmentos en los que el escritor presenta su poética.

Escribe en el blog, Marcelo Recabarren (equipo de la Universidad de Misiones):

"Cuando Sergio me hizo llegar la idea de trabajar el Audio de los podcasts para "Experiencia Cortázar", lo primero que me vino a la cabeza fue "por qué no emular aquellas transmisiones de AM". Decidí darle una estética sonora que tuviera más que ver con el soplido (Hiss) y el ruido de púa tan característico de aquellos años, que con la limpieza de lo digital actual.

Partimos del Diseño Sonoro de las Cortinas y los Cierres, con la voz de un Locutor pasada por plugins de emulación de micrófonos antigüos y un leve soplido propio de la recepción de emisoras radiales de AM.

Para la parte musical, Sergio me pidió un "clima cinematográfico", con una versión grabada en directo de "Ghost for a chance", el tipeo de una máquina de escribir en primer plano, y la locución ya tratada. En el caso de "My blue heaven" en la versión de Ukelele, le agregué ruido de púa para crear un efecto más vinilo retro a la presentación."

\section{Radioteatro}

Emisión en vivo desde LRA Radio Nacional en el marco de los homenajes. Un elenco radial realiza teatro leído con un texto de Cortázar, escrito a pedido "Adiós, Robinson". La magia del lenguaje radiofónico con los textos (las voces), los efectos sonoros se cruzan con la emisión en vivo con público en el auditorio, seguir la señal on line del programa o la posibilidad tecnológica de recuperar el audio y volverlo a disfrutar.

\section{Espacio urbano-espacio ficcional-espacio de la memoria}

Dentro de la propuesta se ofrecían pistas para seguir en mapas interactivos el recorrido cotidiano que realizaba Cortázar durante su estadía en Mendoza; muchos lugares han cambiado pero el juego de las pistas rompía las fronteras del pasado (el ayer en el que el escritor deambulaba por las calles-los paisajes que reconstruyen las fotos y los paisajes en su versión actual) y las del espacio mediático y el físico con pistas dentro del circuito de la U. N. de Cuyo.

\subsection{Casa Tomada: ejemplo de lectura con múltiples sentidos}

Los misterios de Casa Tomada es un documental interactivo a partir de uno de los cuentos más conocidos, en el video se cruzan detalles y fragmentos de entrevistas que dan pistas de las posibles lecturas del cuento; como el mismo autor menciona

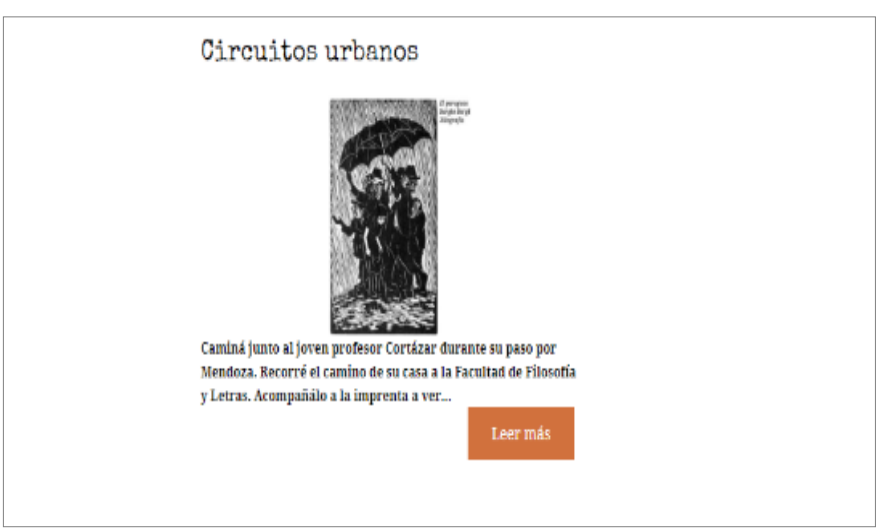

Figura 8. Los circuitos urbanos propuestos. 
Debido al carácter abierto del cuento, "Casa Tomada" se presta a las

múltiples interpretaciones. Algunos hacen una lectura política y biográfica,

diciendo que el cuento es una alegoría al peronismo y a la situación vivida

por el autor que desembocó en su exilio en Europa. Otros, hacen una

lectura psicoanalitica relacionando el concepto de lo ominoso

(unheimlich), trabajado por Sigmund Freud, con aquello que hace que los hermanos huyan de la casa.

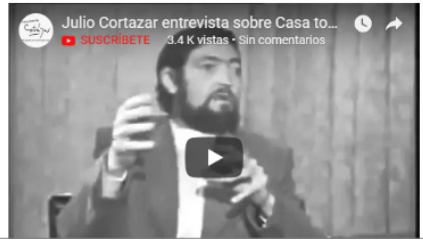

Figura 9. Documental sobre Casa Tomada.

le sorprenden las múltiples lecturas que pueden hacer los lectores que no contradicen el momento de producción.

Un lector de lecturas múltiples y sorprendentes sorprende gratamente al escritor. Como detalle, los textos literarios no están incluidos, un lector que desea saber más busca y lee el cuento si no lo conoce. Audiovisual y texto forman parte del documental interactivo: cada círculo marca una entrada a una explicación posible del misterio del cuento.

\section{Conclusión}

A modo de conclusión, se pueden establecer los siguientes puntos a partir de la descripción del proyecto transmedia.

Se puede sintetizar que Experiencia Cortázar es:

- Un proyecto interdisciplinario que surge como iniciativa independiente dentro de los marcos institucionales de los campos disciplinarios de Comunicación y Tecnología

- El índice de participación implica no una medición numérica en cuanto a un índice de respuesta o de entradas sino a partir de la participación y aportes originales de los "cómplices" a través del contacto con la página: conocer el proyecto, navegar, mudar a otras plataformas sugeridas y finalmente realizar producciones que por el mismo hecho de ser realizadas fuera del marco institucional abren el juego a escenarios diversos y amplios

- El equipo y la experiencia está distribuida entre Mendoza, San Rafael, Buenos Aires y Misiones

- Frente a los límites de la historia de un escritor y su ubicación en el contexto se diagramó una estrategia de participación desde la ficción: si las obras tenían muy pocas referencias a un lugar o a ciertos personajes, se les propuso a los participantes que "completarán desde la ficción", que imaginarán qué sucedió o qué pudo haber pasado cuando el texto literario plantea límites. Este tipo de experiencias también permite este juego ficcional entre los usuarios como creadores. No sólo es documental, sino que es ficción, se presentaron los elementos del parámetro del universo ficcional y se les propuso que completarán con conjeturas y ficciones.

- La accesibilidad tuvo como base herramientas de libre acceso, de uso general preexistentes a la experiencia; la desventaja consistió en el doble registro y en cierta dificultad al utilizar esas herramientas, pero al mismo tiempo el libre acceso posibilitaba que fuera amplia la participación. Es básicamente una causa económica por la misma característica del proyecto: productos no caros que pudie-

\section{El Proyecto}

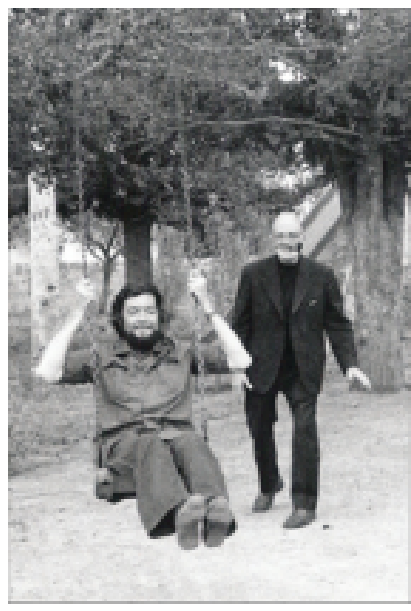

Julio Cortázar y Sergio Sergi - 1973

\section{Buscamos cómplices...}

\author{
"Discurso del no método, método \\ del no discurso, y así vamos.
}

Lo mejor: arrimarse por donde se puede. (...)

De todas maneras vos también
decidirás lo que te dé la gana"

(Julio Cortazar - "Salvo el Crepuisculo", Buenos Aires: E'd. Nueva Imagen, pág. 11)

Figura 10. Presentación del proyecto. 


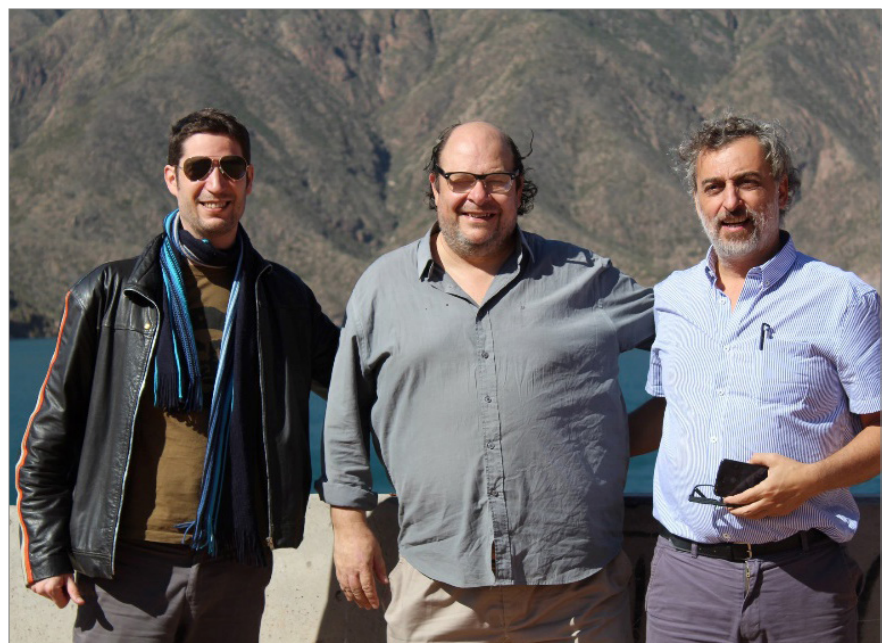

Figura 11. Imagen de Sergio Romero (Mendoza, 23/3/2019) en el centro, junto a Arnau Gifreu y Hernán Cazzaniga. Fuente: Verónica Torres.

ran ser accesibles a través de plataformas de libre acceso. "Demandó mucho trabajo dentro de los límites que nos habíamos propuesto: era un trabajo en una universidad pública sin presupuesto." (Sergio Romero, 16/06/2018)

- Se realizó esta experiencia desde la base colaborativa a nivel de co-autoría

- Se partió desde el concepto de experiencia donde hay migración de contenido de una plataforma a otra:

- "Una cosa muy rica que tampoco se llegó a subir porque no hubo tanta pero que ahora la vamos a subir son los testimonios. Llegó un testimonio de un amigo de su experiencia con Cortázar en la colimba7 en los '70, que cuando llegó y lo vimos dijimos "Ya está. La experiencia está cumplida." Porque tiene una intensidad, recuperó una intensidad personal que seguramente él no cuenta si nadie se la pide, pero con una fuerza narrada que realmente es increíble." (Sergio Romero:16/06/2018)

A partir de las reflexiones de los procesos de convergencia tecnológica y convergencia cultural al explicar los cruces entre los avances tecnológicos como marcos materiales (tecnologías y circulación) con nuevas formas culturales de concebir la relación con la creación (producción) y la interpretación (como experiencia lectora o espectadora) ya no desde una posición pasiva sino como un colaborador, es decir, un destinatario activo y conocedor de la experiencia del ejercicio del derecho a opinar, transformar y finalmente a apropiarse de las obras, rompiendo definitivamente el contrato de lectura que los escritores habían modificado con la nueva narrativa desde el campo de la Literatura.

La narrativa transmedia se introduce en este marco no sólo en los cruces tecnológicos sino como una nueva modalidad de entender los relatos que transitan a través de lo que sostienen y portan las plataformas. En ellas se considera no sólo como una forma de contar sino como una de co-construir eso que se cuenta y como un modo de realizar esos recorridos a partir de decisiones que los usuarios pueden realizar o no y con ello agregar, compartir, intervenir en definitiva un texto.

A través de estas experiencias personales y su traducción en proyectos de narrativa transmedia esas vivencias adquieren otro sentido y la invitación a seguir a Cortázar a través de sus obras, fotos, círculos familiares en sus periplos mendocinos; una propuesta a imaginar la conocida experiencia de leer en el soporte papel e imaginar esos días del cuarenta y pico en los que un joven profesor da clases y escribía relatos que luego serán leídos en muchos países, desde un nuevo rol del lector activo (consumidor proactivo) en un nuevo paradigma que emerge con cambios en la modalidad de interpretar, hacer circular y producir en el contexto de lo digital.

\section{Notas alfinal}

1. Sergio Romero que proviene de las Letras (Facultad de Filosofía y Letras) durante el lapso que llevó el lanzamiento y la vida inicial de la propuesta entre el 2014 y el 2017, se desempeñaba en Universidad Tecnológica Nacional, Regional Mendoza, y la Universidad Nacional de Cuyo.

2. Entrevista a Sergio Romero: Mendoza, 16/6/2018.

3. El material que se ha utilizado de base para este trabajo son los documentos que Sergio Romero nos proporcionó, la propia página de Facebook del proyecto y la realización de una entrevista a Sergio Romero, creador de Exoeriencia Córtazar : Mendoza, $16 / 6 / 2018$

4. Sergio Sergi (Trieste, Italia: 1896-Mendoza,1973) Artista plástico, escultor y amigo cercano de Julio Cortázar en la etapa de Mendoza del escritor. Recuperado en https://ilustracion.fadu.uba. ar/2016/05/24/sergi-sergio/ el 23/06/2018.

5. Entrevista a Sergio Romero, creador y responsable de "Experiencia Cortázar": Facultad de Ciencias Políticas y Sociales de la Universidad Nacional de Cuyo, Mendoza: 16/6/2018.

6. Ibidem Entrevista a Sergio Romero: Mendoza: 16/06/2018.

7. Colimba: servicio militar obligatorio que se cumplió en Argentina hasta la instrucción militar obligatoria que debían cumplir los hombres de entre 16 y 21 años. Fue activo desde 1904 hasta 1994. El término popular era "colimba"

\section{Bibliografía}

Bájtin, M. (1990). El problema de los géneros discursivos en Estética de la creación verbal. Siglo XXI.

Castells, M. (2001). La era de la información. Economía, sociedad y política. La sociedad en red. Alianza Editorial.

Castro, C. (2012) Breves reflexiones sobre narrativa audiovisual para televisión digital y plataformas transmedias. En Campalans, C., Renó, D. y Gosciola, V. (ed.) Narrativas transmedia Entre teorías y prácticas Un estudio de y sobre cultura política. (pp. 85-102). Universidad Nacional de Rosario.

Igarza, R. (2016) Escenas transmediales. Acerca del no diferimiento en el consumo cultural. En F. Irigaray y D. Renó (ed.) Transmediaciones. Creatividad, innovación y estrategias en nuevas narrativas. (pp. 13-22). La Crujía.

Irigaray, F. (2016) Documental transmedia: narrativas espaciales y relatos expandidos. En F. Irigaray y D. Renó (ed.) Transmediaciones. Creatividad, innovación y estrategias en nuevas narrativas. (pp. 


\section{9-54). La Crujía.}

Jenkins, H. (2008). Convergence culture: la cultura de la convergencia de los medios de comunicación. Paidós.

Landow, George P. (2009). Hipertexto 3.0 La teoría crítica y los nuevos medios en una época de globalización. Paidós.

Martínez Gutiérrez, F.(2012). Diálogos interactivos: la evolución del ágora digital. En Campalans, C., Renó, D. y Gosciola, V. (ed.) Narrativas transmedia Entre teorías y prácticas Un estudio de y sobre cultura política. (pp. 27-38). Universidad Nacional de Rosario.

Renó, D. y Ruiz, S. (2012) Reflexiones sobre periodismo ciudadano y narrativa transmedia. En Campalans, C., Renó, D. y Gosciola, V. (ed.) Narrativas transmedia Entre teorías y prácticas Un estudio de y sobre cultura política. (pp. 49-67). Universidad Nacional de Rosario.

Sibilia, P. (2017). La intimidad como espectáculo. Fondo de Cultura Económica.

Scolari, C.A. (2 de marzo de 2017). El translector. Lectura y narrativas transmedia en la nueva ecología de la comunicación. Hipermediaciones.com. https://hipermediaciones.com/2017/03/02/ el-translector-lectura-y-narrativas-transmedia-en-la-nueva-ecologia-de-la-comunicacion/

\section{CV}

Verónica Haydeé Torres. Profesora de Enseñanza Media y Superior en Letras, egresada de la Facultad de Filosofía y Letras. Magister Artium en Literatura Hispanoamericana (Facultad de Filosofía y Letras, UNCuyo:2002), Doctora en Ciencias Sociales (Facultad de Ciencias Políticas y Sociales, UNCuyo:2015). Con formación en Ciencias del Lenguaje (Maestría en Ciencias del Lenguaje (Facultad de Filosofía y Letras, 2003-2005), en comunicación digital (Maestría en Comunicación Digital Interactiva, Universidad Nacional de Rosario: 2018-2019). Sus investigaciones están centradas en el análisis del discurso, comunicación y cultura, periodismo, teoría de la imagen y comunicación digital y producciones audiovisuales.

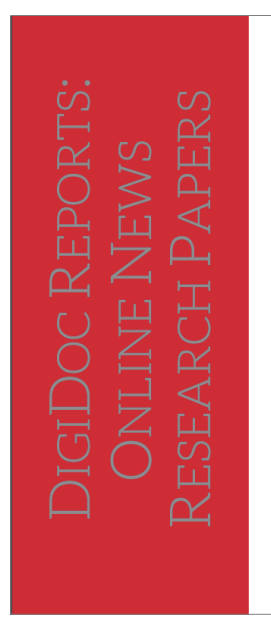

\section{Researching the news in the hybrid media system: An expert panel report} Irene Costera Meijer, Richard Rogers, Oscar Westlund \& Tamara Witschge Pompeu Fabra
Barcelona

Javier Díaz-Noci \& Ana Serrano (eds.)

\section{. Observatorio
de Cibermedios}

https://observatoriocibermedios.upf.edu/

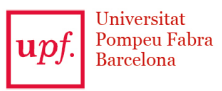

Departamento de Comunicación

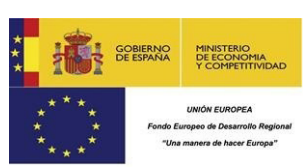

El Observatorio de Cibermedios es una producción del Grupo de Investigación en Documentación Digital y Comunicación Interactiva (DigiDoc) del Departamento de Comunicación de la Universitat Pompeu Fabra.

El Observatorio de Cibermedios (OCM) forma parte del proyecto del Plan Nacional "Narración interactiva y visibilidad digital en el documental interactivo y el periodismo estructurado". RTI2018-095714-B-C21 (MINECO/FEDER), Ministerio de Ciencia, Innovación y Universidades (España). 